\title{
Ethnic differences in incidence of sudden infant death syndrome in Birmingham
}

\author{
D Kyle, R Sunderland, M Stonehouse, C Cummins, O Ross
}

\begin{abstract}
Among the 45204 live births in Birmingham in the three calendar years 1981-3, there were 218 postneonatal deaths, giving a postneonatal mortality rate of 4.82 per 1000 live births. Postneonatal mortality rates were $\mathbf{4 \cdot 2 2}$ for whites, 5.91 for Asians (relative risk 1.26, $95 \%$ confidence interval (CI) 1.04 to 1.53 ) and 8.20 for Afro-Caribbeans (relative risk 1.78, $95 \% \mathrm{Cl} 1.25$ to $2 \cdot 55$ ). Among Asians malformations were common (3.36) and sudden infant death syndrome rare $(1 \cdot 18)$, in contrast to Afro-Caribbeans among whom the rates were 0.66 and $5 \cdot 25$, respectively.

Logistic regression analysis demonstrated a significantly lower risk of sudden infant death syndrome (SIDS) in Asians and significantly raised risks of SIDS in very low birthweight babies and those with unemployed parent(s).

Ethnic differences persisted after controlling for maternal age, social class, and birth weight. Studies of sociocultural differences in child rearing practices are needed and may uncover important aetiological factors of sudden infant death syndrome.
\end{abstract}

Despite the fact that north/south differences in postneonatal mortality rates have evened out, there remain important differences among regions, especially between deprived inner city communities and the more privileged who live in the suburbs and shires. ${ }^{1}$ The principal cause of postneonatal mortality is now the sudden infant death syndrome (SIDS). In attempting to identify priorities for its prevention, studies have recommended attention to health care services, the importance of educating parents in child care, ${ }^{2}$ the infant's sleeping position, ${ }^{3}$ and have examined social aspects such as maternal age and legitimacy. ${ }^{4}$ The possibility that ethnic factors may have a role is raised by some studies. ${ }^{5-10}$

This paper examines the postneonatal course of all children born in Birmingham between 1981 and 1983 from the results of interviews between parents and health visitors.

\section{Subjects and methods}

Details of the birth and survival during the first year of all children born to mothers resident in Birmingham are recorded in the Birmingham birth register, a continuing record based on returns made by midwives, health visitors, child screening, and mortality records. Ethnic group is assigned by the health visitor after personal contact with the parents and thus differs from the Office of Population Censuses and Surveys (OPCS) classification, which is by mother's country of birth. ${ }^{11} 12 \mathrm{~A}$ considerable advantage of this classification over that of the OPCS is that second generation ethnic births are identified by our method. This is particularly important in Birmingham, as $40 \%$ of the AfroCaribbean births in the city in 1981-3 were to women who had been born in the United Kingdom. These mothers are 'English' yet their babies are black; similarly Asian immigrants from east Africa are 'African' but their babies are brown. Differing genetic and sociocultural influences are better reflected by our method than by arbitrary assignation by the mother's place of birth.

Infants were classified into one of four groups, white, Asian (Indian, Pakistani, or Bangladeshi), Afro-Caribbean, and other (including oriental and those of mixed ethnic origin).

The Birmingham Births Register has available details of all births and deaths of children known to be resident in Birmingham, irrespective of place of birth or death. Most of the migration of children in the first year of life occurs between different parts of the City of Birmingham and would thus pose no problem. If a child resident in Birmingham subsequently moved out of the City in their first year of life, however, and then succumbed elsewhere, it is possible that the details of their death would not be known to the register. This should only affect the results if there was significant differential migration out of the city of those babies more or less at risk of SIDS, or of different ethnic groups, which we do not think is likely.

Social class was coded to include both single and two parent unemployed families as 'other' social class, on the grounds that unemployment may be categorised as a 'poorer' social condition than unskilled manual employment.

Full details of children who died between 1 month and 1 year of age were obtained for all children born in 1981-3 inclusive, and the cause of death was assigned from these records. These were the most recent years for which complete records were available for the whole of Birmingham. Only cases recorded as 'sudden infant death syndrome' on the death certificate were included as such. All sudden infant deaths in Birmingham are referred to HM Coroner, and all have necropsies by one of a small group of pathologists, all of whom are trained in techniques of paediatric necropsy. Assigning cause of death directly from mortality data rather than from coded national statistics is another impor- 
tant difference between this and the OPCS national study. ${ }^{11}$ As SIDS is essentially a diagnosis of exclusion, accuracy of certification and coding are vital. In large scale studies of childhood mortality there is evidence of invalid death certification, as well as errors in the coding of death certificates by lay clerks, and confounding changes in the classification of the causes of death. ${ }^{13} 14$

Statistical analysis was carried out by estimating the relative risks of postneonatal mortality and SIDS in the different ethnic groups, calculating $95 \%$ confidence intervals $(\mathrm{CI})^{15}$ and the Mantel-Haenszel test. ${ }^{16}$ The Mantel-Haenszel estimates of relative risk after controlling for ethnic group were calculated, and Mantel's extension of the Mantel-Haenszel test was used to test for trends after controlling for ethnic group. A logistic regression analysis of SIDS deaths among babies surviving beyond 28 days was also carried out.

\section{Results}

Numbers of live births and details of postneonatal deaths for each ethnic group are shown in table 1. There were no deaths in this period that could not be linked to birth data. Asian names, particularly as recorded on birth notification forms, are difficult to link to other data. In this study, however, it was possible to match the birth register record with the health visitor record, which contained the information from which the birth register records were coded. In difficult cases matching was done not only on name, but also on other variables such as mother's date of birth, parity, hospital of birth, birth weight, and original address. The overall relative risks for postneonatal death were: AfroCaribbean compared with white $1 \cdot 78$ (95\% CI $1 \cdot 25$ to $2 \cdot 55)$, and Asian compared with white 1.26 (95\% Cl 1.04 to 1.53$)$.

The relative risks for postneonatal death excluding SIDS were: Afro-Caribbean compared with white 1.41 (95\% CI 0.77 to 2.59$)$, and Asian compared with white $1.71(95 \% \mathrm{Cl}$ 1.40 to 2.08 ). The relative risk of dying from a congenital malformation for Asians compared with whites was 2.07 (95\% $\mathrm{Cl} 1.67$ to 2.56 ).

Breakdown of the SIDS by ethnic group and social class, maternal age, birth weight, and number of persons/room in the household are given in table 2 .

The relative risk of SIDS in Afro-Caribbean compared with white infants was $2 \cdot 09(95 \% \mathrm{Cl}$ 1.35 to 3.24$)$. The relative risk in Asian compared with white infants was $0.61(95 \% \mathrm{Cl} 0.37$ to 1.01 ).

After controlling for ethnic group, and subdividing birth weight into less than $2500 \mathrm{~g}$ ('low birth weight') and $2500 \mathrm{~g}$ and over ('normal birth weight') the increased Mantel-Haenszel relative risk for SIDS was not significant $(\mathrm{r}=1 \cdot 78,95 \% \mathrm{Cl} 0.92$ to $3 \cdot 41)$.

Testing for trends in SIDS with maternal age and social class after controlling for ethnic group, we found a significant trend with decreasing maternal age (log rank $\chi^{2}=22 \cdot 47$, df $1, p<0.001$ ) and lower social class (log rank $\chi^{2}=23.24$, df $\left.1, p<0.001\right)$. There was no

Table 1 Number (ratel1000 live births) of postneonatal deaths among Birmingham births 1981-3 by ethnic group and cause

\begin{tabular}{|c|c|c|c|c|}
\hline & \multicolumn{4}{|l|}{ Ethnic group } \\
\hline & White & Asian & Afro-Caribbean & Other \\
\hline $\begin{array}{l}\text { No of live births } \\
\text { No of postneonatal deaths: } \\
\text { Infection } \\
\text { Congenital malformations } \\
\text { Sudden infant death syndrome } \\
\text { Accident } \\
\text { Malignant disease } \\
\text { Prematurity } \\
\text { Other }\end{array}$ & $\begin{array}{r}27944 \\
118(4 \cdot 22) \\
16(0 \cdot 57) \\
25(0 \cdot 89) \\
63(2 \cdot 25) \\
3(0 \cdot 11) \\
3(0 \cdot 11) \\
2(0 \cdot 07) \\
6(0 \cdot 21)\end{array}$ & $\begin{array}{r}10999 \\
65(5.91) \\
8(0.73) \\
35(3.18) \\
13(1 \cdot 18) \\
1(0.09) \\
1(0.09) \\
0 \\
7(0.64)\end{array}$ & $\begin{array}{r}3049 \\
25(8 \cdot 20) \\
5(1 \cdot 64) \\
2(0 \cdot 66) \\
16(5 \cdot 25) \\
1(0 \cdot 33) \\
0 \\
0 \\
1(0 \cdot 33)\end{array}$ & $\begin{aligned} & 3212 \\
& 10(3 \cdot 11) \\
& 3(0.93) \\
& 2(0 \cdot 62) \\
& 4(1 \cdot 25) \\
& 0 \\
& 0 \\
& 0 \\
& 1(0.31)\end{aligned}$ \\
\hline
\end{tabular}

Table 2 Number (rate/1000 live births) of postneonatal deaths from sudden infant death syndrome among Birmingham births 1981-3 by ethnic group, social class, maternal age, and birth weight

\begin{tabular}{|c|c|c|c|c|}
\hline & \multicolumn{4}{|c|}{ Ethnic group } \\
\hline & White & Asian & Afro-Caribbean & Other \\
\hline $\begin{array}{l}\text { Social class: } \\
\text { I/II } \\
\text { III } \\
\text { IV/V } \\
\text { Other }\end{array}$ & $\begin{array}{r}4(0 \cdot 87) \\
27(1 \cdot 76) \\
13(3 \cdot 32) \\
19(4 \cdot 61)\end{array}$ & $\begin{array}{l}0 \\
5(1 \cdot 44) \\
5(1 \cdot 14) \\
3(1 \cdot 44)\end{array}$ & $\begin{array}{r}2(9 \cdot 35) \\
1(0 \cdot 80) \\
3(7 \cdot 54) \\
10(8 \cdot 45)\end{array}$ & $\begin{array}{l}0 \\
0 \\
0 \\
4(2 \cdot 80)\end{array}$ \\
\hline $\begin{array}{c}\text { Maternal ag } \\
<20 \\
20-35 \\
\geqslant 35\end{array}$ & $\begin{array}{r}16(5 \cdot 16) \\
44(1 \cdot 93) \\
3(1 \cdot 47)\end{array}$ & $\begin{array}{r}1(1 \cdot 10) \\
11(1 \cdot 22) \\
1(0 \cdot 90)\end{array}$ & $\begin{array}{r}6(7 \cdot 41) \\
10(4 \cdot 74) \\
0\end{array}$ & $\begin{array}{ll}2 & (2 \cdot 97) \\
2 & (0.84) \\
0 & \end{array}$ \\
\hline $\begin{array}{l}\text { Birth weigh } \\
<2500 \\
\geqslant 2500\end{array}$ & $\begin{array}{r}5(2 \cdot 47) \\
58(2 \cdot 24)\end{array}$ & $\begin{array}{r}2(1 \cdot 67) \\
11(1 \cdot 12)\end{array}$ & $\begin{aligned} 6 & (16 \cdot 44) \\
10 & (3 \cdot 73)\end{aligned}$ & $\begin{array}{l}0 \\
3^{*}(1.04)\end{array}$ \\
\hline $\begin{array}{l}\text { Persons/roon } \\
\quad<1.5 \\
\geqslant 1.5\end{array}$ & $\begin{array}{l}51(2 \cdot 12) \\
10(3 \cdot 17)\end{array}$ & $\begin{array}{l}6(0.98) \\
6(1.41)\end{array}$ & $\begin{array}{r}11(4 \cdot 85) \\
5(7 \cdot 09)\end{array}$ & $\begin{array}{l}3(1.62) \\
0\end{array}$ \\
\hline
\end{tabular}

*One for whom birth weight unknown was excluded.

tExcluded if number not known. 
Table 3 Logistic regression analysis of SIDS deaths in babies surviving at least 28 days

\begin{tabular}{lccc}
\hline Independent variable & Coefficient & Odds ratio & $\begin{array}{l}95 \% \\
\text { Confidence interval }\end{array}$ \\
\hline Asian* & & 0.620 & 0.295 to 0.981 \\
Afro-Caribbean & 0.537 & 0.538 & 0.964 to 3.040 \\
Other non-white & -1.157 & 1.712 & $0 \cdot 098$ to 1.013 \\
$\geqslant 1.5$ persons/room & 0.071 & 0.314 & 0.642 to 1.797 \\
Birth weight $\geqslant 1500<2500 \mathrm{~g}$ & 0.439 & 1.074 & 0.822 to 2.926 \\
Birth weight* $<1500 \mathrm{~g}$ & 1.836 & 1.550 & 2.269 to 17.341 \\
Maternal age <20 & 0.269 & 6.273 & 0.773 to 2.213 \\
Maternal age $\geqslant 35$ & -0.460 & 1.308 & 0.087 to 4.597 \\
Social class I or II & -0.156 & 0.631 & 0.395 to 1.853 \\
Social class IV or V & 0.403 & 0.856 & 0.838 to 2.670 \\
No employed parent(s) & 0.852 & 1.496 & 1.414 to 3.887 \\
Sex & 0.049 & 2.344 & 0.702 to 1.572 \\
\hline
\end{tabular}

Coefficient/SE $\geqslant 2$

significant association between overcrowding (persons/room in the household $\geqslant 1.5$ ) and SIDS. This was also true after controlling for ethnic group $(\mathrm{r}=1 \cdot 43,95 \% \mathrm{Cl} 0.81$ to $2 \cdot 51)$.

The logistic regression analysis was carried out using babies surviving at 28 days as the population and a SIDS death before the first birthday as the outcome. The dependent variables in the model were Asian ethnic origin, Afro-Caribbean ethnic origin, ethnic origin other than both parents of white, Asian or AfroCaribbean origin, household with at least 1.5 persons per room, birth weight $\geqslant$ to $1500 \mathrm{~g}$ and $<2500 \mathrm{~g}$, birth weight $<1500 \mathrm{~g}$, mother aged $<20$, mother aged $\geqslant 35$, social class I or II, social class IV or V, and no social class coded (that is, no working parent in household). The model produced had no significant departures from a good fit to the data and the regression coefficients, odds ratios, and approximate confidence limits produced are given in table 3 .

Only the variables Asian ethnicity, birth weight less than $1500 \mathrm{~g}$, and no employed parent reach conventional levels of significance. Asian ethnicity is associated with a significantly low risk of SIDS, while very low birth weight and unemployment are associated with a significantly increased risk of SIDS. Afro-Caribbean ethnicity had a relatively increased risk of SIDS of $1 \cdot 712$, but this just fails to reach conventional levels of significance.

\section{Discussion}

In contrast to previous studies of postneonatal mortality in Birmingham, ${ }^{17}{ }^{18}$ the results of this study show that there has been a significant increase in postneonatal mortality among infants of Afro-Caribbean and Asian ethnic groups compared with whites. Among AfroCaribbeans this is largely the result of an increased risk of SIDS, and among Asians the risk of SIDS is lower than among whites, but there is an excessive number of deaths from congenital malformations. The previously reported slight increase in 'cot deaths' among Asians has not been confirmed. ${ }^{18}$

The expected trend of increased SIDS with decreasing maternal age and lower social class is independent of ethnic group. In the logistic regression analysis, the raised relative risks for maternal age $<20$ and social class IV and V, and the decreased relative risk for maternal age $\geqslant 35$ and social class I and II were not significant. Children in families with unemployed parent(s) were at significantly increased risk of SIDS. This suggests that maternal age is a marker for other socioeconomic factors.

These results confirm the findings of Griffiths et al of increased postneonatal mortality in Afro-Caribbean infants in central Birmingham health district, ${ }^{9}$ and show it is largely attributable to SIDS. Analysis of postneonatal deaths by cause (table 1) after studying the detailed mortality records gives no evidence of a diagnostic substitution-say of respiratory infection for SIDS in white or Asian infants. This finding confirms work from the United States, ${ }^{56}$ but is in contrast to the findings of Balarajan et al for the whole of England and Wales. " They found the incidence of SIDS among infants of mothers born in the Caribbean was similar to that among infants whose mothers were born in the United Kingdom. The different method of assigning ethnic group could explain this. The difference could also be explained if the immigrant mothers had different child rearing practices or social environments from subsequent generations.

Like Balarajan $e t a l$, we found that the combination of Afro-Caribbean and Asian infants into an 'Afro-Asian' group was unhelpful. Asian babies have about half the rate of SIDS that whites do. There is no evidence to support the statement of Milner and Ruggins that there is a 'low incidence of sudden infant death syndrome in the "Afro-Asian" babies in England and Wales'. ${ }^{12}$ Both Balarajan et al and Fedrick (from Oxford) ${ }^{19}$ report similar or even higher rates of SIDS in babies of 'Caribbean' and 'West Indian' born mothers, respectively.

In the United States high rates of SIDS among Afro-Caribbean populations are attributed in part to less favourable birth weights and socioeconomic circumstances. ${ }^{20}$ In this study in the United Kingdom, ethnic differences in rates of SIDS are not totally attributable to socioeconomic factors as measured by social class. We have found in a multivariate analysis that Asians still have a reduced risk of SIDS. Very low birthweight babies have a significantly increased risk. Socioeconomic influences were most strongly expressed in children with unemployed parent(s).

The high mortality rate for malformations among Asians and the low rate among AfroCaribbeans are consistent with previous studies of perinatal mortality. ${ }^{21}$

Poor social circumstances have been found to be an important contributory cause in most 
studies of SIDS. Analysis of those in Birmingham in both $1958-61^{18}$ and $1981-3$ shows that most deaths occurred in families resident in geographical areas identified as the most deprived. Yet deaths occurred in other parts of the city, and most of the children living in deprived geographical areas do not succumb, which argues against serious local environmental hazards. Lee et al suggested that overcrowded households confer an advantage, providing a continuous stimulus to the baby. ${ }^{8}$ We found no significant relationship between overcrowding and SIDS, either overall or within any ethnic group using either MantelHaenszel techniques or logistic regression analysis. Although $38 \%$ of Asian babies in Birmingham in 1981-3 were born to mothers living in households with more than 1.5 persons/room, compared with $12 \%$ of white babies, $23 \%$ of the Afro-Caribbean babies were also born to mothers living in such crowded households. The change from a low rate of SIDS among Afro-Caribbean babies in 1958-61 to a high rate in 1981-3 suggests changes in social rather than genetic factors. Although in the logistic regression analysis this just failed to reach conventional levels of significance there may well be social factors other than overcrowding affecting child care practice in the AfroCaribbean group which lead to an increased risk of SIDS. The lack of any social class gradient in Asian SIDS babies (table 2) suggests (as did Lee et $a l^{8}$ ) that cultural factors may be protective. One of the striking features of the Asian community in Birmingham is the strength and endurance of the extended family.

Further study of the differences in mortality in clearly identifiable subgroups of the population may assist in unravelling some of the continuing questions in the aetiology of SIDS.

We thank Professor EG Knox and the department of social medicine for access to the Birmingham births data, Dr R Whittington
(HM Coroner for Birmingham) for his hēp, Dr I Rushton and Dr $M$ Braddick for helpful comments about the manuscript, and Mrs April Kirk for typing it.

1 Gordon RR, Sunderland R. Equality in death: disappearance of differences in postneonatal mortality between northern and southern regions of England and Wales. Br Med $\mathrm{f}$ 1987;295:528-9.

2 Knowelden J, Keeling J, Nicholl JP. Postneonatal mortality. London: DHSS, 1985 .

3 de Jonge GA, Engelberts AC, Koomen-Liefting AJM, Kostense $\mathrm{PH}$. Cot death and prone sleeping position in the Netherlands. Br Med $\mathcal{F}$ 1989;298:722.

4 Gordon RR, Sunderland R. Maternal age, illegitimacy and postneonatal mortality. Br Med F 1988;297:774.

5 Golding J, Limerick S, Macfarlane A. Sudden infant death patterns, puzzles and problems. Shepton Mallet: Open Books, 1985

6 Black L, David RJ, Brouillette RT, Hunt CE. Effects of birth weight and ethnicity on sudden infant death syndrome. $\mathcal{F}$ Pediatr 1986;108:209-14.

7 Davies DP. Cot death in Hong Kong: a rare problem? Lancet 1985;ii:1364-8.

8 Lee NNY, Chan YF, Davies DP, Lau E, Yip DCP. Sudden infant death syndrome in Hong Kong: confirmation of low incidence. $\mathrm{Br}$ Med $\mathcal{F}$ 1989;298:721.

9 Griffiths $R$, White $M$, Stonehouse M. Ethnic differences in birth statistics from central Birmingham. Br Med f 1989; 298:94-5.

10 Gordon RR. Postneonatal mortality among illegitimate children registered by one or both parents. Br Med $\mathcal{F} 1990 ; 300$ : dren re $236-7$.

11 Balarajan R, Sari Raleigh V, Botting B. Sudden infant death syndrome and postneonatal mortality in immigrants in England and Wales. Br Med $\mathcal{F}$ 1989;298:716-20.

12 Milner AD, Ruggins N. Sudden infant death syndrome. $B$ Med f 1989;298:689-90.

13 Sunderland R, Sunderland EP. Invalid certification of young deaths. Arch Dis Child 1983;58:867-71.

14 Sunderland $R$. Inaccurate coding corrupts medical information. Arch Dis Child 1985;60:593-4.

15 Morris JA, Gardener MJ. Calculating confidence intervals for relative risks (odds ratios) and standarised ratios and rates. Br Med F 1989;296:1313-6.

16 Armitage P, Berry G. Statistical methods in medical research. 2nd Ed. Oxford: Blackwell, 1987.

17 Davison WH. Accidental infant suffocation. Br Med $\mathcal{F} 1945$; ii:251-2.

18 Cameron AH, Asher P. Cot deaths in Birmingham 1958-61. Med Sci Law 1965;5:187-99.

19 Fedrick J. Sudden unexpected death in infants in the Oxford record linkage area: the mother. British fournal of Prevenrecord linkage area: the mother. British

20 Kraus JF, Greenland S, Bulterys M. Risk factors for sudden infant death syndrome in the US collaborative perinatal project. Int $\mathcal{f}$ Epidemiol 1989;18:113-20.

21 Terry PB, Condie RG, Bissenden JG, Kerridge DR. Ethnic differences in incidence of very low birthweight and neonatal deaths among normally formed babies. Arch Dis Child 1987;62:709-11. 